\title{
Creative Reflections: How Students Find Meaning in Unexpected Clinical Experiences
}

\author{
Kristina L. Leyden*, Lucindra Campbell-Law*, Loan Nguyen, Mary Donna Piazza
}

Carol and Odis Peavy School of Nursing, University of St. Thomas, 3800 Montrose Boulevard, Houston, TX 77006-4626, United States.

\author{
Article Details \\ Article Type: Research Article \\ Received date: $7^{\text {th }}$ August, 2018 \\ Accepted date: $12^{\text {th }}$ November, 2018 \\ Published date: $17^{\text {th }}$ November, 2018
}

"Corresponding Author: Dr. Kristina Leyden, Dr. Lucindra Campbell-Law, Carol and Odis Peavy School of Nursing, University of St. Thomas, 3800 Montrose Boulevard Houston, TX 77006-4626, United States. E-mail: leydenk@stthom.edu or cambpel1@stthom.edu

Citation: Leyden K, Campbell-Law L, Nguyen L, Piazza MD (2018) Creative Reflections: How Students Find Meaning in Unexpected Clinical Experiences. J Comp Nurs Res Care 3: 131. doi: https://doi.org/10.33790/jenrc1100131.

Copyright: $\mathbb{C} 2018$, This is an open-access article distributed under the terms of the Creative Commons Attribution License 4.0, which permits unrestricted use, distribution, and reproduction in any medium, provided the original author and source are credited.

\begin{abstract}
Background: Nursing students exposed to clinical experiences may have intense feelings during required clinical preparations. Art can provide a source of relief from demands of caring for varieties of patients [1]. Little research exists on benefits of art to facilitate nursing students to process unexpected events. Faculty at a faithbased, liberal arts University introduce creative reflection to help find meaning in unexpected clinical experiences.
\end{abstract}

Aim: The aim of this paper is to discuss the application of creative reflection across BSN courses.

Method: Creative reflection was first offered in the Adult MedicalSurgical Course. Positive feed back led faculty to add creative reflection to the pediatric course after pediatric burn clinical rotation; to the Behavioral Health course for understanding of mental health issues; and in Foundations for coping with grief concepts.

Results: Students reported this type of expression meaningful in the unexpected, often difficult,clinical experience.

Conclusion: Creative reflections offer students an alternative outlet to process unexpected clinical experiences. Students report many benefits, including finding meaning in suffering, death, and ability to "de-stress". Introducing creative reflections may give students an "outlet" for coping which could lead to prevention of nursing burn-out.

Keywords: Trauma, Debriefing, Closure, Symbolism, Healing, Holism, Finding Meaning, Self-Awareness, Instrument of Healing, Burn-out

\section{Introduction}

Nursing students often encounter unexpected situations taking care of patients from diverse backgrounds and health conditions; therefore, it is important to give these students a means to reflect on their clinical experiences and a way to process any unexpected experience. For the purposes of this article, unexpected experience is operationally defined as something the student is subjectively experiencing and typically outside the physicality of nursing. Examples of unexpected experiences include difficulty with a patient death, a pediatric burn victim, someone experiencing psychosis, a volatile patient or co-worker/preceptor, and, but not limited to, difficulty with conflict management or resolution.

This paper describes how faculty at a faith-based, liberal-arts University are creating healing environments for students enrolled in a baccalaureate-holistic-nursing program. The focus on integrating creative reflection through art in the curriculum is seen as a way to help nursing students find meaning in unexpected clinical experiences. This paper will describe how creative reflection art was implemented in several nursing courses in order to create a healing environment for students.

\section{Background and Significance}

Creating art can increase awareness of self and others. When one increases awareness of self and others, personal development, increase coping skills, and enhanced cognitive function occur. Art, when used for this purpose, is defined as art therapy. Art therapy is a way to obtain a resolution with issues, reduce stress, and manage one's feelings. Furthermore, its use can help the user understand one's own emotions through this art expression. According to creative art experts, the expression of art allows oneself to heal with an understanding of self [2].

\section{Art Reflection in Nursing Care}

There is a significant amount of literature on the use of reflection in clinical settings. The most common form of reflection used include verbal or written debriefing $[3,4]$.

There is significant amount of literature on the subject of creative reflection and its use in patient populations to help process and make sense of traumatic events. According to Lloyd, Wong and Petchkovsky [5] and Van Lith [6], art therapy has long been used in mental health settings and substance abuse treatment programs as a means for patients to cope with traumatic events. A study was conducted utilizing existing data from national substance abuse treatment programs. The sample consisted of a total of 299 programs which evaluated art and music therapy in patient care. Art therapy was categorized as a form of complementary and alternative medicine (CAM). The researchers reported that a significant relationship existed for those substance abuse treatment modalities and the use of art therapy [7].

The use of creative reflection has benefits in several populations and communities. There is growing support for the use of art in children suffering from trauma who do not have the words to express their emotions [8]. Some researchers suggest that children be allowed to create art without the interpretation and involvement of a licensed psychotherapist and that the use of the creative process may be in itself therapeutic [9]. Additional research supports the use of art with patients with terminal illness to help them deal with their diagnoses and serve as a way to help them find meaning in their illness [10,11]. 
More recently, the benefits of using creative art therapy are being explored for military veterans who have suffered trauma or injuries during service [12]. For example, in the aboriginal community, expressive art and storytelling is used as a form of cultural identity and as a means to promote familial health [13]. The common thread "phil rouge" in the literature is the positive effect of art on healing.

\section{Integrating Art Reflection in Curriculum}

There is support for incorporating some type of creative component in nursing courses to help students improve communication with patients [14], development of empathy [15,16], reasoning [17], and self-awareness $[1,18]$, or help place patients in the best position for healing [19]. Verbal or written reflection assignments have long been integrated in nursing curriculum to aid the student in critical thinking, problem solving and critical reasoning. This practice is centered around patient care and often identifies needs for improvement in patient care $[3,4]$. It is generally accepted nurses should participate in some form of reflection and is focused on the patient outcomes, so far, art has not been an option as a way to reflection on clinical experiences.

More recently, findings support the use of creative art in clinical settings as a means to aid communication between nursing students and patients [20]. To meet the needs of students and support their learning in mental health nursing, a metropolitan University, in Melbourne Australia developed the stARTalking program. The starting program was a health initiative designed to complement student learning and foster creativity. The aim of this stArtalking program was to prepare students to engage patients in the behavioral health clinical settings as well as enhance critical thinking, communication and interpersonal skills [21]. However, the focus remain on the patient, not the student.

\section{Student Self Reflection}

There is very little evidence as to what benefits may be to teach students to use creative reflection for their own self-care. Some examples of reported self reflection include one individual's experience with anxiety, multiple sclerosis, and diabetes. Art therapy helped aid this individual's life and give her ways to cope in daily living, help her find contentment and meaning [22]. One art therapist reports the use of art therapy as a coping mechanism to facilitate healing [23].

Denhartog [24] reported on the benefits of creativity through art from one nurse's perspective. This nurse used art to cope with personal panic attacks. Art helped her decrease stress and dealt with stressful days while working in a pediatric ward. In this example, this nurse uses art to cope with personal issues and not necessarily with stressors in the clinical arena. One can glean that if there are so many benefits for creativity and art in patient care which give patients hope, help patients cope with debilitating diseases, relieve pain, and improve immunity [25] then the same benefits may help students or nurses cope and find meaning in unexpected clinical experiences.

\section{Theoretical Underpinning}

The creative process allows the individual to subconsciously release those traumatic events and even help to make sense of them. Many times nursing students who are beginning their clinical rotation are thrown in the realities and must bear witness to substantial patient trauma, emotional disturbances, and others. Observing and treating these traumas can prove overwhelming for nursing students. Helping students find meaning in unexpected clinical experiences contribute to treating the student in a holistic manner, and essentially modelling desired behaviour towards the patient.

\section{Logotherapy}

The work of Frank1 [26] on logotherapy can serve as the foundation of assisting nursing students to find meaning in unexpected clinical experiences. Frankl shared his experience endured in captivity in concentration camps. He believed that all persons have the need to find the meaning of life and that suffering can lead to meaning. He suggests one way to express this meaning can come through art [26]. This integration of creative reflection through the use of art into nursing curriculum aligns with Frankl's logotherapy because it allows students to find meaning in unexpected clinical experiences [26].

\section{Symbolism in Art}

Symbolism is best known as a literary element used in literature to enable readers to understand a literary work. Symbolism is most often used as means to reveal emotions, thoughts and feelings at a deeper, more abstract level. According to researchers, the origin of symbolism dates back to the 17th century and has been employed in a variety of ways throughout the centuries. Often the concepts of emotion, mood, or of a certain thought are expressed in the techniques of symbolism and can involve the use of art as creative reflection [27].

Symbols used to express emotion are easily illustrated by color. St. Clair [28] explored symbolic colors through the biology of how people see color and how color has been portrayed in historical aspects or used. Pleij [29] explains the use of color more deeply while evaluating concepts of color used in paintings. Red is used when portraying anger, power, love and passion. Blue represents peace or sadness. Green illustrates growth and nature. White symbolizes innocence or purity. On the other hand, black is used when the tone is symbolic of death or evil [30].

\section{Methodology}

Nursing student reflective practice was required in several courses across the curriculum in a baccalaureate-nursing program at a private, faith-based, liberal-arts University. The aim of the reflection assignment was to help the student to develop critical thinking skills and sensitivity to their patient, themselves, and others in the clinical environment. Much of the criteria was based on Facione's work on critical thinking and clinical reasoning [4] and Patricia Benner's [3] work on the nurses' developmental stages.

Creative reflection through art was introduced as an option to a written reflective exercise to incorporate the therapeutic value for patients, expressed in literature, and translating it to the debriefing of nursing students on difficult, meaningful, or traumatic events witnessed during clinical rotations while fulfilling "self-reflection" criteria. These students had opportunities to work with varying patients, situations, and environments. Students reflected on patients with acute diseases, cancer, patient codes, death, psychiatric illness, burns, and developmental delays. Students encountered these patients in a variety of settings, including, psychiatric intensive care units, prison, pediatric burn hospital, step-down, transplantation, oncology, stroke, rehabilitation, and geriatric units. Positive student response commanded faculty to adopt it across four clinical courses at both the Junior and Senior level.

Creative reflection was first offered as an option to one of three required reflections in the Fall 2012 and Fall 2013 Adult MedicalSurgical course. The strain of intense reflections within a 7-day clinical rotation lead faculty to require only two reflections, with an option for one of those to be in a creative medium in the Fall 2014 and 2015. The requirements were further reduced to one creative reflection in Fall 2016.

A creative reflection option was first offered in the Paediatric course in Spring 2015 and in the Behavioural Health course Fall 2016. In Spring 2016 Paediatric course, student were required to submit a creative reflection after their rotation through a paediatric burn unit. In Fall 2017, this reflective component was required in the Behavioural Health course. Students presented their work to faculty one on one following well-developed faculty guidelines and a grading rubric. The purpose of this creative reflection was to facilitate the course learning objectives on the experience of loss, death, and grief. In Summer 2016, a similar reflection piece, using 


\begin{tabular}{|l|l|l|l|l|}
\hline Course & Year & \# of Students & Required & Optional \\
\hline Medical Surgical & Fall 2012 & 3 & & x \\
\hline & Fall 2013 & 6 & & x \\
\hline & Fall 2014 & 7 & & x \\
\hline & Fall 2015 & 11 & & x \\
\hline & Fall 2016 & 11 & & x \\
\hline Pediatrics & Spring 2015 & 34 & x & \\
\hline Pediatrics & Spring 2016 & 35 & x & \\
\hline & Spring 2017 & 37 & x & \\
\hline & Spring 2018 & 27 & x & \\
\hline Foundations & Summer 2016 & 38 & x & \\
\hline & Summer 2017 & 27 & x & \\
\hline Behavioral Health & Fall 2016 & 16 & & x \\
\hline & Fall 2017 & 37 & x & \\
\hline
\end{tabular}

Table. Course Implementation with Participating Students

the same faculty guidelines and grading rubric, was offered in the fundamentals course. Course implementation with participating students can be seen in the Table.

\section{Study Design}

A descriptive, non-experimental study design was used to describe how students reflective process as they shared their clinical experiences and if those experiences impacted their critical thinking.

\section{Population}

Undergraduate, Bachelors of Science in Nursing (BSN) students in their Junior and Senior year were the population for this assignment. The faculty members teaching juniors (Adult, Adult/Older Adult, and Pediatric courses) and faculty teaching one of the senior level courses (Behavioral Health course).

\section{Sampling}

A purposeful/convenience sampling method was used. Nursing students in the sample were already enrolled in the course and the creative reflection component was a requirement of the courses.

\section{Procedure}

Students presented their work to faculty, individually, following well-developed faculty guidelines and a grading rubric.

\section{Results}

Students allowed themselves to be vulnerable with their stories and personal journey toward healing. Students reflected on varying situations. Some of these situations were perceived difficulty with a preceptor, witnessing a dying patient, dressing changes in a pediatric burn patient, patients suffering from mental illness or substance abuse, or other unexpected clinical situations. Students were evaluated using the Creative Piece Rubric (Appendix). The tool was developed by the authors with expertise in visual communication and curriculum design. The tool was piloted in a previous Adult course. It was modified to clearly define scoring criteria. The tool was validated using interrater reliability. Cumulative scores ranged from 80-100.

The students used various forms of expressive art to share their unexpected experience. The students' theme and perspective varied. Most students depicted the experience from the patient's point of view as if they were looking outward to express the pain, despair, suffering, and hope they endured. From this perspective, students were able to tell the patients' story through colors, symbolism, and wording.
An example of the use of symbolism and colors, in an untitled piece, was a painting in which the student depicted a silhouette of a person colored blue, crouching on the edge of a cracked cliff. The background was a rainbow of colors which indicated moving the viewer from despair to hope. Over the edge of the cliff were the dark colors of the rainbow representing falling into the darkness and despair. The person was crouched over the red to orange portion of the rainbow to symbolize sensitivity of emotions, a fragile balance, and danger. Immediately behind the person, was a tree, half dead and half alive which symbolized the child's struggle to live. Next to the tree, was a musical note indicating happiness. Imposed on top, the scene was a rainbow of colors that represented managing the care of the patient (Figure 1).

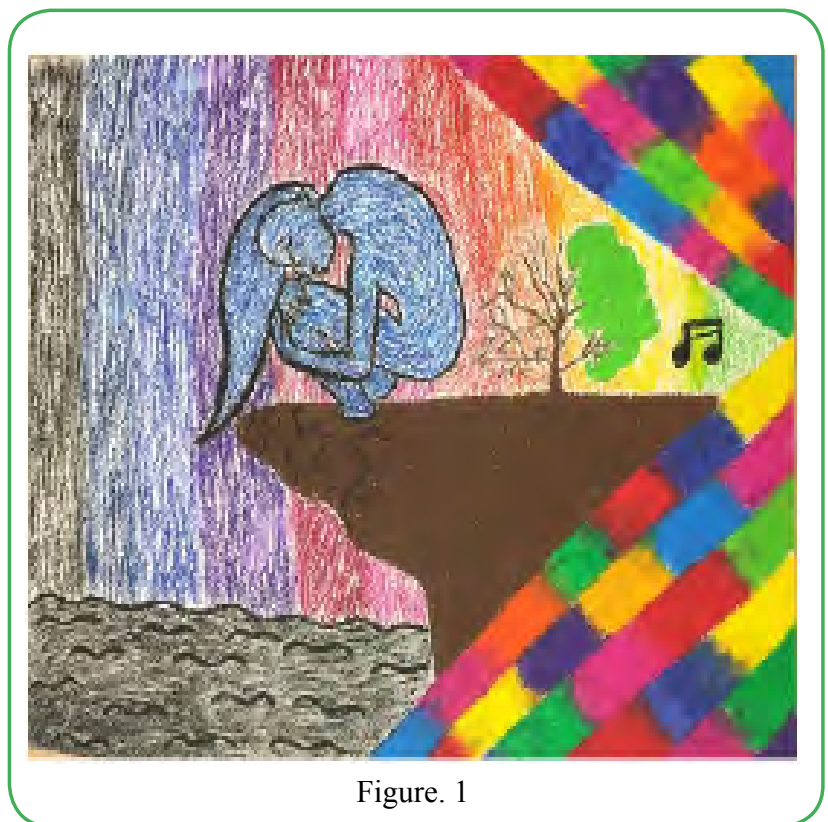

Other students used the assignment to look inward and explore their identity as a nurse and interpret how this experience can alter their perception of themselves and their relationships with others. One student, in particular, created a handmade origami box. Three types of paper were used to create the box: Blue denim symbolized conservativeness, brown wood-like paper represented a sense of enclosure, and paper with imprinted keys represented a locked box. 
For the student, this symbolized strength and opening up of oneself from the locked box. The box was filled with delicately made origami. Fish were symbolic of perseverance and courage; cranes symbolic of hope, healing, and happiness; and lamas symbolic of strength and hard work (Figure 2).

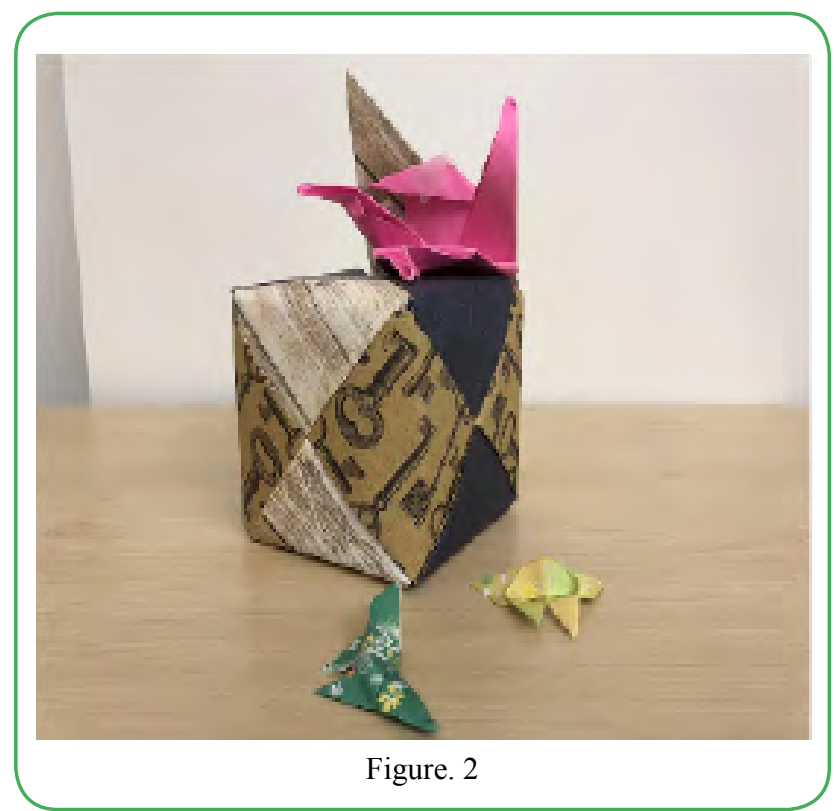

There were other students who depicted perspectives of the patient's fears and struggles and of their own feelings and emotions about the experience. An example of this is a painting where the student effectively used two different colored silhouettes to represent her and the patient. The painting represented the nurse's negative reaction to her patient when the patient was physically distraught. The silhouettes stood back to back in the middle of the canvas.

The nurse was the dark silhouette. This indicated she was closed off and represented the pain and blurriness of the situation. The child, on the other hand, was colorful and surrounded in darkness. The darkness was the burns indicating the patient was suffering. Separating the two figures was a vine and flower, representing life and growth and the need for nurturing for both the patient and the nurse. The vine extended to the top of the canvas and split going both directions. On the nurse's side entwined in the vine was a red heart with a tear representing compassion. The patient's vine had a chain with a locked lock. The chain represents the patient's current situation (Figure 3).

\section{Student Testimonies}

Students reported different emotions when describing their reflections. Students revealed the creative reflections helped them to find meaning in trauma, put closure to the difficult cases witnessed and find understanding in death. One student reported having negative feelings when learning about having to complete the assignment; however, she felt "liberated" and more aware of how much the clinical experience affected her psyche. Here are some examples of what students had to say about their experiences and how the use of this strategy helped them process their experiences in the clinical setting. One student reported, "this [assignment] helped me, as a nursing student, to physically express what I have been observing and absorbing emotionally and physically while being in the behavioral health setting." Another student shared, "sitting down and creating this piece, without having to be so clinical and technical that you have to be when doing a written reflective journal, provided me with the opportunity to relieve myself of all that I had absorbed in clinical."

Other students internalized their experience, "I personalized [the patient] symptoms and stories with myself...working on the reflection piece really helped me think back and reflect on everything and everyone I saw, and thus giving me inner peace and closure." Another example of this internalization, "I was ... able to reflect and process aspects of my own life as well as the role I have as a future nurse to facilitate healing. I soon realized that my barrier to caring for them and being [fully] present with them stemmed from my past. I saw glimpses of my old wounds, hurts, and pains in theirs."

Another student used this experience to express the unknown, "the black dripping on the left side of the painting is me looking into the unknown and having to face the mystery of this new experience." This student expressed the emotions that she encountered and the symbolism that it represented in the art piece. A student shared "this creative reflection helped me release the emotional trauma I experienced in taking care of this burned child, the piece helped me have closure."

Here is an example of a student who, initially, had doubts about this type of assignment, "I was skeptical on the usefulness of this project, I didn't see the point of it; but, when I was done, I had no idea I was feeling what I did, I had no idea I was so stressed and sad about my experience; somehow doing this project helped me understand what I was feeling and in some way understand the trauma my patient went through, and even my own..."

In the end, this student reported it to be exactly what was needed to help her find meaning in a difficult clinical experience and gave her the tools to take care of herself during stressful times in school and her future career.

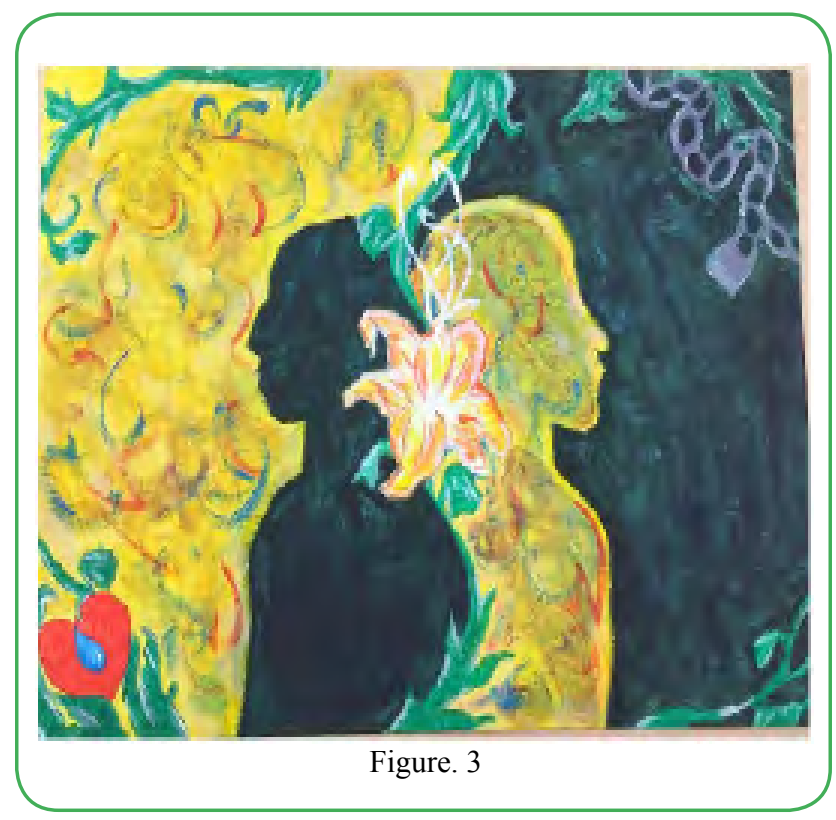

\section{Conclusion}

Creative reflections have offered students an alternative outlet for debriefing or dealing with traumatic or unexpected clinical experiences. Students report the benefits and own mental health in completing the creative reflections. Students report finding meaning in suffering, death, and illness. Students report ability to "de-stress" using this method. Introducing creative reflections may give students an "outlet" for coping which could lead to prevention of nursing burn-out. Faculty found it a useful, innovative method to facilitate students expression in dealing with unexpected clinical experiences.

\section{Discussion}

Threading creative reflection in these four courses throughout curriculum is a way to help students process unexpected clinical experiences. Not aiding students in processing unexpected experiences could put the students at risk for increased stress. There 
is a plethora of findings regarding the significance of stress. Stress, one of the largest health problems, subsequently leads to exhaustion, burnout, and a weakened immune system. Most recently, authors Martin et al. [31] report art interventions are an innovative way to prevent stress and improve stress management. Based on faculty observations, it is suggested that creative reflection be integrated into baccalaureate nursing education both in the classroom and clinical setting.

\section{Conflict of Interest}

Authors report there is no conflict of interest of any kind and attests to the originality of this work.

\section{References}

1. Jones EK, Kittendorf AL, Kumagai AK (2017) Creative art and medical student development: a qualitative study. Medical Edu 51: 174-183.

2. Ulman, E (2001). Art therapy: Problems of definition. Am J Art Therapy 40: 16-26.

3. Benner P (1984) From novice to expert: Excellence and power in clinical nursing practice. Am J Nurs 82: 402-407.

4. Facione NC, Facione PA (2008) Critical thinking and clinical reasoning in the health sciences: An international multidisciplinary teaching anthology. California Academic Press, Millbrae, California.

5. Lloyd C, Wong SR, Petchkovsky L (2007) Art and recovery in mental health: A qualitative investigation. Brit J Occup Therapy 70: 207-214.

6. Van Lith T (2016) Art therapy in mental health: A systematic review of approaches and practices. The Arts in Psychotherapy 47: 9-22.

7. Aletraris LP, Paino M, Edmond MB, Roman PM, Bride BE et al. (2014) The use of art and music therapy in substance abuse treatment programs. J Addict Nurs 25: 190-196.

8. Hussain S (2010) Art therapy for children who have survived disaster. Virtual Mentor 12: 750-753.

9. Losinski M, Hughey J, Maag JW (2016) Therapeutic art: integrating the visual arts into programming for students with emotional and behavioral disorders. Beyond Behav 25: 27-34.

10. Cervoni E (2011) 'A man paints with his brains and not with his hands' (Michelangelo). Gerontol 57: 572.

11. Stuckey HL, Nobel J (2010) The connection between art, healing, and public health: A review of current literature. Am J Pub Health 100: 254-263.

12. Walker MS, Kaimal G, Koffman R, DeGraba TJ (2016) Art therapy for PTSD and TBI: A senior active duty military service member's therapeutic journey. The Arts in Psychotherapy 49: 10-18.

13. Nilson C, Kearing G, Fetherston C, Morrison P (2015) Art from the heart: Using art narrative to describe the experiences of a health promotion program in an Australian aboriginal community. Int J Arts Theory History 10: 13-32.

14. Calman K, Downie R (1996) Why arts courses for medical curricula. Lancet 347: 1499-1500.

15. Nilson C (2008) Using the emotion of art to build cohesion, collaboration and empathy between student nurses. Paper presented at the Teaching and Learning Forum. Curtin University.

16. Potash JS, Chen JY, Lam CL, Chau VT (2014) Art-making in a family medicine clerkship: how does it affect medical student empathy? BMC Med Edu 14: 247.
17. Carroll M, Curtis L, Higgins A, Nicholl H, Redmond R et al. (2002) Is there a place for reflective practice in the nursing curriculum? Nurse Edu Pract 2: 13-20.

18. Burnard P (1995) Nurse educators' perceptions of reflection and reflective practice: a report of a descriptive study. J of Adv Nurs 21: 1167-1174.

19. Schwind JK, Beanlands H, Lapum J, Romaniuk D, Fredericks $S$ et al. (2014) Fostering person-centered care among nursing students: Creative pedagogical approaches to developing personal knowing. J Nurs Edu 53: 343-347.

20. Rice R, HunterJ, Spies M, Cooley T (2017) Perceptions of Nursing Students Regarding Usage of Art Therapy in Mental Health. J Nurs Edu 56: 605-610.

21. Ward L, Barry S (2016) stARTalking: Undergraduate mental health nursing education and art. Nurse Edu Pract 21: 107-113.

22. Hom C (2018) The power of art therapy. Story Library.

23. Belanger M (2018) Therapeutic process through art, selfreflection and visual processing. Story Library.

24. Denhartog L (2015) The art of healing. Alberta RN 71: 32-33.

25. Lane MR (2005) Creativity and spirituality in nursing: Implementing art in healing. Holistic Nurs Pract 19: 122-125.

26. Frankl V (1992) Man's search for meaning: An introduction to logotherapy (4th ed.). Beacon Press, Boston, Massachussetts.

27. MacBean AC (2013) Art and symbolism: The technique of applying hidden meaning and communicating specific ideas through art.

28. St Clair K (2016) The secret lives of color. Penguin Books. New York, New York.

29. Pleij H (2004) Colors demonic and divine: Shades of meaning in the Middle Ages and after. Columbia University Press, New York, New York.

30. Empower Yourself with Color (2018) Understanding the Meaning of Colors in Color Psychology.

31. Martin L, Oepen R, Bauer K, Nottensteiner A, Mergheim K, Gruber H, Koch SC (2018) Creative arts interventions for stress management and prevention-a systematic review. Behav Sci 8: 28. 
Appendix

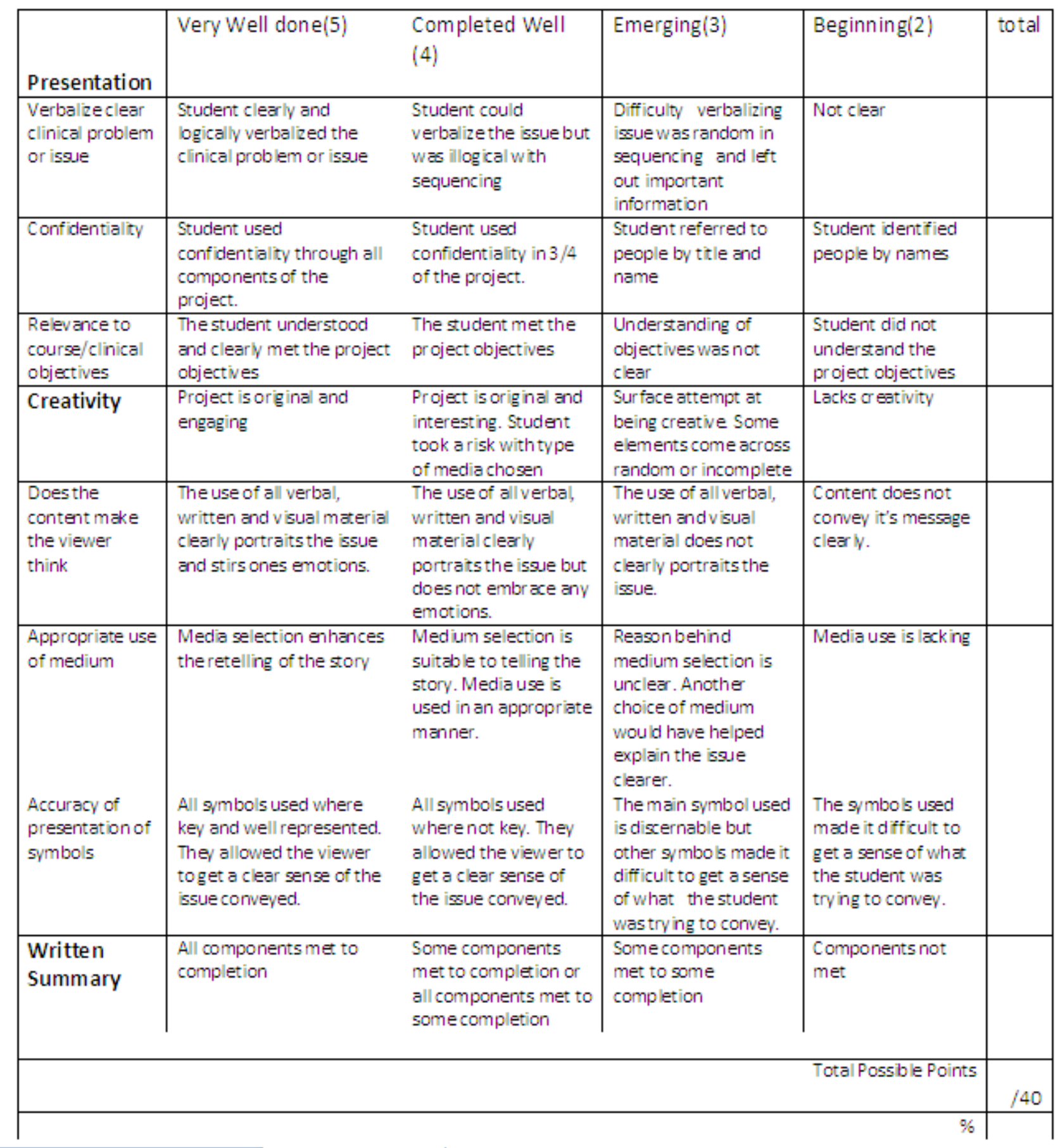

